\section{IMPLEMENTATION OF FALLS PREVENTION OF OLDER PEOPLE IN THE CITY OF LAHTI}

'Pirkko Heinonen, 'liris Salomaa, 'Tiina Lehtinen, ${ }^{2}$ Satu Pajala. 'City of Lahti, Finland, ${ }^{2}$ National Institute for Health and Welfare, Finland

\subsection{6/injuryprev-2016-042156.100}

Background Falls and related injuries are a major public health concern in elderly people in Finland. Despite extensive knowledge base about prevention of falls, widespread and systematic falls prevention was insufficient at Lahti City Social and Health Care services. Along with the structural change of Social and Health Care services, starting in 2014, implementation of falls prevention and reducing the falls incidence was set into one of the strategic goals.

Objective IKINÄ - model was chosen as a framework for the implementation and developing local fall prevention practices. The emphasis is on organised and systematic multiprofessional fall risk assessment, risk-assessment-based planning and execution of necessary interventions. Implementation was initiated with analysing the falls, practices of recording the falls and skills and competence of the health care staff.

Results One to two fall prevention and implementation champions have been trained from each nursing home units, home care and acute/rehabilitation wards (altogether 98 staff members). Head of each unit is liable for deployment of implementation in co-operation with the staff. Practices and scales for systematic fall risk factor assessment have been put into operation.

Conclusions Target of the outcome and benefits of implementation are all citizens of Lahti and 1300 social and healthcare staff members. After two years, systematic fall risk assessment has become fixed procedure. Documentation of falls, risk factors, patient safety incident reporting and preventive work has improved. Daily physical activity and exercise has become a norm in units. The implementation is an ongoing process. Next follow-up survey will be done in spring 2016 and incident of falls and fall injuries are monitored regularly.

\section{COST-EFFECTIVENESS OF VITAMIN D AND EXERCISE IN PREVENTING INJURIOUS FALLS AMONG OLDER WOMEN}

\begin{abstract}
${ }^{1}$ Radhika Patil, ${ }^{1}$ Päivi Kolu, ${ }^{1,2}$ Jani Raitanen, ${ }^{3,4,5,6}$ Jaakko Valvanne, ${ }^{1,3,7}$ Pekka Kannus, ${ }^{1}$ Saija Karinkanta, ${ }^{1}$ Harri Sievänen, ${ }^{1,8}$ Kirsti Uusi-Rasi. ${ }^{1}$ The UKK Institute for Health Promotion Research, Tampere, Finland; ${ }^{2}$ School of Health Sciences, University of Tampere, Finland; ${ }^{3}$ School of Medicine, University of Tampere, Finland; ${ }^{4}$ Purchasing Committee for the Promotion of Senior Citizens' Welfare, City of Tampere, Finland; ${ }^{5}$ Gerontology Research Centre, Universities of Jyväskylä and Tampere, Finland; ${ }^{6}$ Department of Internal and Respiratory Medicine, Tampere University Hospital, Finland; 'Department of Trauma, Musculoskeletal Surgery and Rehabilitation, Tampere University Hospital, Finland; ${ }^{8}$ Research Department, Tampere University Hospital, Finland
\end{abstract}

\subsection{6/injuryprev-2016-042156.101}

Background Costs of falling in older persons are high, both to individuals and to society. Both vitamin D and exercise are suggested to reduce the risk of falls. This study assessed the costeffectiveness of vitamin D supplementation and exercise, separately and combined, in preventing medically attended injurious falls among older Finnish women.

Methods Economic evaluation was conducted alongside a previously published 2-year randomised controlled trial where 409 community-dwelling women aged 70 to 80 years were recruited into four groups: 1) no exercise + placebo (D-Ex-) 2) no exercise + vitamin D $800 \mathrm{IU} /$ day $(\mathrm{D}+\mathrm{Ex}-)$ 3) exercise + placebo
$\left.(\mathrm{D}-\mathrm{Ex}+)_{4}^{4}\right)$ exercise + vitamin D $800 \mathrm{IU} /$ day $(\mathrm{D}+\mathrm{Ex}+)$. Outcomes were medically attended injurious falls and fall-related health care utilisation costs over the intervention period, the latter evaluated from a societal perspective based on 2011 unit costs. Incremental cost-effectiveness ratios (ICER) were calculated for the number of injurious falls per person-year prevented, and uncertainty estimated using bootstrapping.

Results Incidence rate ratios $(95 \% \mathrm{CI})$ for medically attended injurious falls were lower in both Ex + groups compared with $\mathrm{D}-\mathrm{Ex}-: 0.46$ (0.22 to 0.95$)$ for $\mathrm{D}-\mathrm{Ex}+, 0.38$ (0.17 to 0.81$)$ for $\mathrm{D}+\mathrm{Ex}+$. Step-wise calculation of ICERs resulted in exclusion of $\mathrm{D}+\mathrm{Ex}-$ as more expensive and less effective. Recalculated ICERs were $€ 221$ for $\mathrm{D}-\mathrm{Ex}-, € 708$ for $\mathrm{D}-\mathrm{Ex}+$ and $€ 3,820$ for $\mathrm{D}$ + Ex + ; bootstrapping indicated $93 \%$ probability that each injurious fall avoided by $\mathrm{D}-\mathrm{Ex}+$ per person-year costs $€ 708$. At a willingness to pay of $€ 3,000$ per injurious fall prevented, there was an $85.6 \%$ chance of the exercise intervention being costeffective in this population.

Conclusions Exercise was effective in reducing fall-related injuries among community dwelling older women at a moderate cost. Vitamin D supplementation had marginal additional benefit. The results provide a firm basis for initiating feasible and cost-effective exercise interventions in this population.

\section{Fire Safety and Burn Injuries}

\section{Parallel Mon 1.6}

\section{A SYSTEM FOR IMPROVED BURN INJURY SURVEILLANCE IN RESOURCE-LIMITED SETTINGS}

${ }^{1}$ David Sugerman, ${ }^{1}$ Henry Falk, ${ }^{2}$ David Meddings, ${ }^{3}$ Sumi Mehta, ${ }^{4}$ Michael Peck, ${ }^{1}$ Michael Sage. ' US Centresfor Disease Control and Prevention, Atlanta, GA; ${ }^{2}$ World Health Organisation, Geneva; ${ }^{3}$ Global Alliance for Clean Cookstoves, Washington, DC; ${ }^{4}$ University of Arizona, Phoenix, AZ

\subsection{6/injuryprev-2016-042156.102}

Background There are limited and fragmented data collection systems for burn injury. A global repository may lead to better burn injury estimates and help identify key risk factors. A collaborative effort involving the World Health Organisation (WHO), the Global Alliance for Clean Cookstoves, the U.S. Centres for Disease Control and Prevention (CDC), and the International Society for Burn Injuries was undertaken to simplify and standardise in-patient burn data collection. Utilising an expert panel of epidemiologists and burn care practitioners, a new form and online data entry system was developed which can be used in resource-abundant or resource-limited settings. The Global Burn Registry (GBR) form has three functions: 1) to determine the magnitude and risk factors for burns, 2) provide baseline and follow up data to test primary prevention interventions, and 3) be designed for use without modification around the world.

Methods After development, international burn organisations, CDC and WHO solicited burn centre participation to pilot test the GBR system. WHO and CDC led a webinar to describe system implementation.

Results During an 8 month period, 55 hospitals in 29 countries enrolled in the pilot and were provided the GBR instrument, guidance, and data visualisation tool. Evaluations were received from 29 hospitals (53\%). Key findings were: median time to upload completed forms was less than 10 minutes; physicians most commonly entered data (64\%), followed by nurses $(25 \%)$; 